HORTSCIENCE 26(7):902-904. 1991.

\title{
Chromosome Analysis of Alstroemeria ligtu Hybrids
}

\author{
Patricia Rustanius ${ }^{1}$, A. Hang ${ }^{2}$, H.G. Hughes ${ }^{1}$, and T. Tsuchiya ${ }^{2}$ \\ Colorado State University, Fort Collins, CO 80523
}

Additional index words. karyotype, genome, Peruvian lily, cut flowers

\begin{abstract}
Five color types of Alstroemeria ligtu Linn hybrids from one seed source were examined cytogenetically. The somatic chromosome numbers were all $2 \mathrm{n}=$ $2 x=16$. Karyotype analysis revealed that all five plants had the same chromosome constitution. Chromosome pairs 2,3,5, and 8 had satellites. Chromosome complements of the A. ligtu hybrid were unique in that they contained two pairs of satellite metacentric chromosomes that were not found in any Alstroemeria cultivars.
\end{abstract}

There are many cultivars of alstroemerias available to commercial growers (Thompson, 1986); however, most Alstroemeria cultivars currently available are sterile hybrids developed from interspecific crosses and mutation breeding (Broertjes and Verboom, 1974; Healy and Wilkins, 1985).

Chromosome studies on the genus $\mathrm{Al}$ stroemeria began in 1882 when Strasburger studied microspore development of $\mathrm{A}$. chilensis Cree (Broertjesan and Verboom, 1974; Taylor, 1926; Whyte, 1929). Similar investigations were conducted throughout the century but most were chromosome counts. Until recently, extensive cytological analysis had not been performed for the genus (Hang and Tsuchiya, 1988; Tsuchiya and Hang, 1987; Tsuchiya et al., 1987). The A. ligtu hybrids

Received for publication 3 July 1989. This study was supported by Colorado Agriculture Experiment Station Project 604. The cost of publishing this paper was defrayed in part by the payment of page charges. Under postal regulations, this paper therefore must be hereby marked advertisement solely to indicate this fact.

'Dept. of Horticulture.

${ }^{2}$ Dept. of Agronomy. are believed to be interspecific hybrids involving A. ligtu Linn and two or more species (Uphof, 1952). The exact parentage and origin of crosses are unknown.

Our objective was to analyze the chromosomes of the A. ligtu hybrids with the development of an idiogram as a basis for comparison to other alstroemeria species. Meiotic chromosome behavior and pollen fertility were also studied.

We obtained the A. ligtu hybrids as rhizomes (Sun Valley Bulbs, Arcata, Calif.). We used five plants in this study, one each with yellow, pink, orange-pink, orange, or white flowers. The plants had originated as individual seedlings from a single seed pack sent to Sun Valley Bulbs. The seeds had been collected from plants of reputed A. ligtu hybrids, the hybrid crosses having been made several generations ago, but details of seed collection and exact parentage were unavailable (L. Carrier, personal communication, Sun Valley Bulbs).

Plants were grown in a 1 peat : 1 perlite : 1 soil mixture (by volume) to facilitate the collection of root tips. Growing conditions included natural daylengths in the greenhouse that ranged from $11 \mathrm{C}$ at night to 


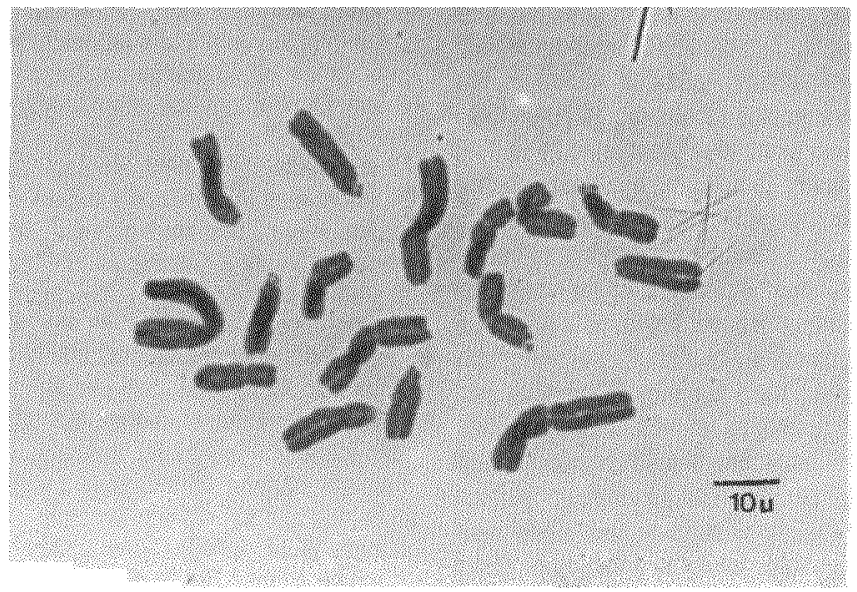

Fig. 1. Somatic metaphase chromosomes of Alstroemeria ligtu hybrid (orange), Bar indicates $10 \mu \mathrm{m}$.

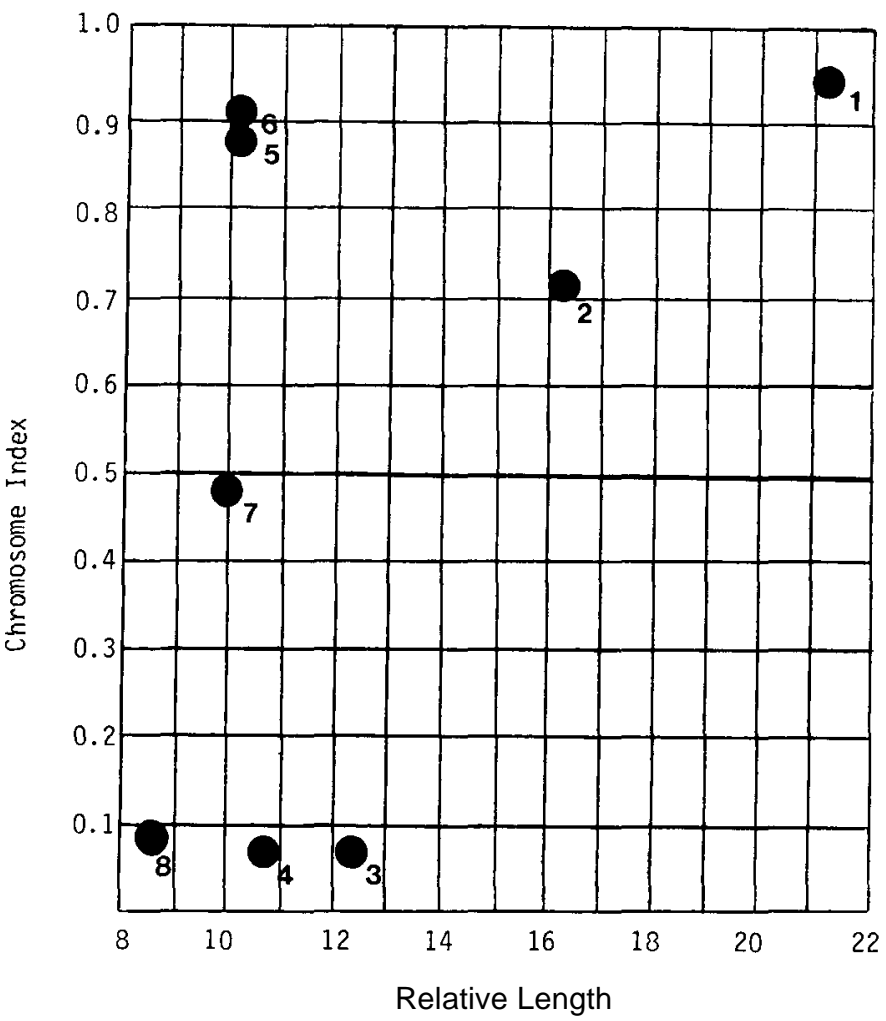

Fig. 2. Diagrammatic presentation of the Alstroemeria ligtu hybrid genome. Relative lengths (x-axis) were derived by averaging the percentages of total chromosome length for individual chromosomes of the five genomes. The chromosome index is the average of the short-arm to long-arm ratios of the five hybrids (y-axis).

a maximum of $28 \mathrm{C}$ during the day. Root tips were collected from Mar. 1985 to Feb. 1986. Time of collection did not seem to affect results so the root tips were collected at 4:00 PM. Actively growing plants were carefully removed from the pots. Root tips $\approx 4 \mathrm{~mm}$ long were cut and placed into small vials with distilled water. Vials were then placed in ice water and maintained at $4 \mathrm{C}$ for 16 to $18 \mathrm{~h}$. Preliminary observations showed that $18 \mathrm{~h}$ of cold gave nicely constricted chromosomes that were easy to separate, but some of the small satellites were no longer visible. Cold exposure of $<16 \mathrm{~h}$ resulted in poor contraction of chromosomes, making chromosome separation difficult.

After the cold treatment, the root tips were fixed in $395 \%$ ethanol :1 glacial acetic acid $(\mathrm{v} / \mathrm{v})$ at room temperature for 3 to $24 \mathrm{~h}$. The roots were then stained with acetocarmine $(0.7 \%$ carmine in $45 \%$ acetic acid). After 24 to $48 \mathrm{~h}$, preparations were made using Tsuchiya's modified acetocarmine squash method (Tsuchiya, 1971). Staining for $24 \mathrm{~h}$ resulted in root tips that were easy to squash, but chromosomes that were not stained darkly. At $48 \mathrm{~h}$, the chromosomes were well stained, but root tips were very soft. Longer staining times yielded root tips that were extremely difficult to squash.

A minimum of 10 cells per plant was used to determine the chromosome number. The karyotype analysis was made using one representative cell from each plant in which the chromosomes were well separated and secondary constrictions visible. Cells with the desirable chromosome conditions were photographed at $\times 800$ magnification under oil using a Carl Zeiss Photomicroscope II (Zeiss, Oberkochen, Germany). Photomicrographs were printed at a magnification of $\times 1000$.

The chromosomes of the photographed cells were numbered from 1 , the longest one, to 16 , the shortest. To measure the chromosomes, a fine thread was laid over each chromosome in the photograph, marked, then measured in millimeters. All measurements were conducted twice. Since all of the satellites were shorter than $1 \mathrm{~mm}$, they were not included in the measurements. Homologous pairs were arranged by comparing centromere positions and presence of satellites.

Averages of the paired chromosomes were taken for total length, relative length, index, and ratio. A genome karyotype was thus obtained for each A. ligtu hybrid studied. A relative value was used as the standard for chromosome lengths. The relative length of a given chromosome was determined by dividing the absolute chromosome length by the sum of all the chromosome lengths and was expressed as a percentage of the total (Tjio and Hagberg, 1951).

The ratio of long arm to short arm was used to identify centromere position for each chromosome. The nomenclature system of Levan et al. (1964) was used to determine the chromosome type as median, submedian, or subterminal. Diagrammatic presentations for the five plants were developed according to arm ratios and relative lengths. The idiogram representing the ligtu hybrids was based on averages for relative lengths and arm ratios.

The five plants derived from reputed $A$. ligtu hybrids used in this study had 16 somatic chromosomes $(2 \mathrm{n}=2 \mathrm{x}=16)$. Karyotype analysis revealed that the five plants differing in flower color showed the same chromosome constitutions. A somatic cell with 16 chromosomes in a typical plant (orange flower type) is represented in Fig. 1, All five flower color types were averaged to develop the diagrammatic presentation of the derived A. ligtu hybrid genome (Fig. 2).

The chromosomes were grouped into two classes, those with satellites and those without. There were four pairs of satellite chromosomes, numbers 2, 3, 5, and 8. The idiogram (Fig. 3) showing these chromosomes was based on the five plant genomes.

The two metacentric or submetacentric chromosome pairs with satellites (pair numbers 2 and 5) were not found in any of the 20 European and five American cultivars studied thus far (Hang and Tsuchiya, 1988; Tsuchiya and Hang, 1987; Tsuchiya et al., 1987). This absence suggests that the A. ligtu hybrids might have not been used to produce the European and American alstroemeria cultivars studied thus far.

There are many accounts of A. ligtu hybridizing with other Alstroemenia species. Some of the species assumed to be involved in hybridization are A. angustifolia Herbert, 


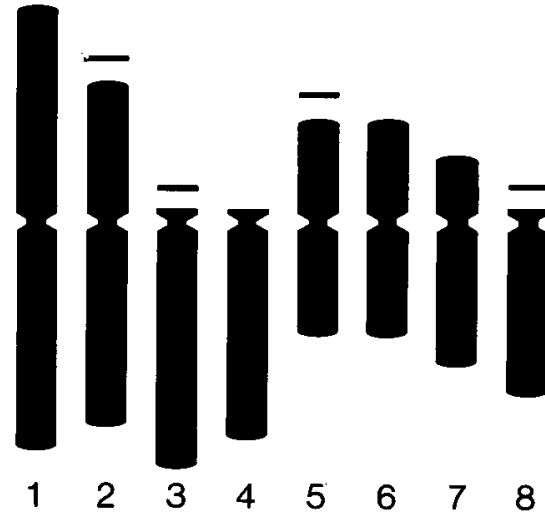

Fig. 3. Idiogram of the Alstroemeria ligtu hybrid genome.

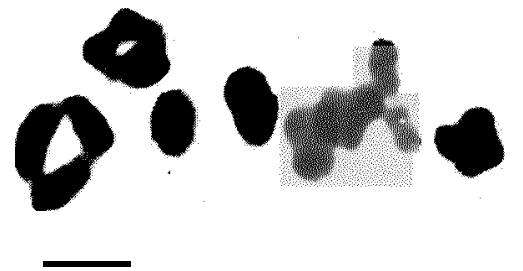

Fig. 4. Meiotic metaphase I observed in a pollen mother cell of A. ligtu hybrid (orange). Seven of the eight bivalents were closed-ring structures. Bar indicates $10 \mu \mathrm{m}$.

A. aurantiaca Don., A. chilensis, A. haemantha Ruiz and Par., and $A$. versicolor Ruiz and Par. (Ballard, 1952; Errey, 1962; Goodspeed, 1940; Hannibal, 1941; James, 1940; Robinson, 1963). Therefore, it is likely that A. ligtu hybrid karyotypes from a variety of seed sources would differ. More detailed analysis, including biochemical analysis, is necessary to determine the origin of the five plants derived from A. ligtu hybrids.

It is possible that some of the species of alstroemeria are actually only ecotypes showing different phenotypes. There are 62 recognized species in the genus Alstroe- meria, with its center of distribution in South America (Uphof, 1952). The heterogeneous environment of South America provides for population divergence (Zohary, 1970), making alstroemeria ecotypes possible. If the $A$.

ligtu hybrids were produced by interspecific crosses, some hybrids should have shown irregular meiotic pairing in early hybrid generations. This event seems likely since most of the cultivars, derived from interspecific crosses, examined thus far show irregular pairing and low pollen fertility (Tsuchiya and Hang, 1987; Tsuchiya et al., 1987). Since the A. ligtu hybrids form a high percentage of bivalents (Fig. 4) and have high pollen fertility, it is likely that they are now well established as cytologically homozygous lines as a result of generations of selections after original hybridization.

Although the analysis of these plants ( $A$. ligtu hybrids) did not provide information on the pedigrees of the European alstroemeria cultivars, it is apparent that the hybrid genome is distinct and could be identified in cultivars through karyotype analysis. These hybrids contain distinct chromosome pairs (numbers 2 and 5) with median or submedian centromeres and secondary constrictions with small satellites. No cultivars of European or American origin have yet been observed to have the median or submedian centromeres and secondary constrictions with small satellites.

The chromosome constitution of the hybrids would be explained if the A. ligtu species and other seed sources of A. ligtu hybrids could be analyzed. A preliminary observation of the karyotype of $A$. ligtu species indicated that at least one pair of medium-sized submedian chromosomes with satellites in the hybrids (number 5) was derived from A. ligtu species (T.T. and A.H., unpublished data). However, more research on the A. ligtu species and various $A$. ligtu hybrid lines is necessary to deter-mine the origin of A. ligtu hybrids.

\section{Literature Cited}

Ballard, W.R. 1952. A try at alstroemerias. Plant
Life: Herbertia Ed. 8:108-109.

Broertjes, C. and H. Verboom. 1974. Mutation breeding of Alstroemeria. Euphytica 23:39-44.

Errey, G. 1962. Alstroemeria hybrids. Hort. Soc. 87:547.

Goodspeed, T.H. 1940. Amaryllidaceae from the University of California expeditions to the Andes. Plant Life: Herbertia Ed. 8:17-31.

Hang, A. and T. Tsuchiya. 1988. Chromosome studies in the genus Alstroemeria II. Chromosomes constitutions of eleven additional cultivars. Plant Breeding 100:273-279.

Hannibal, L.S. 1941. Stinson and his alstroemerias. Plant Life: Herbertia Ed. 8:161-165.

Healy, W.E. and H.F. Wilkins. 1985. A1stroemeria culture. Minn. State Florists Bul. 33:38.

James, W.M. 1940. Growing alstroemerias from seeds. Plant Life: Herbertia Ed. 7: 169-171.

Levan, A., K. Fredga, and A.A. Sandberg. 1964. Nomenclature for centromeric position on chromosomes. Hereditas 52:201-220.

Robinson, G.W. 1963. Alstroemeria. Hort. Soc. 88:490-494.

Taylor, W.R. 1926. Chromosome morphology in Fritillaria, Alstroemeria, Silphium and other genera. Amer. J. Bot. 13:179-193.

Thompson, W. 1986. Production potential. Greenhouse Manager 5:60-68.

Tjio, J.H. and A. Hagberg. 1951. Cytological studies on some X-ray mutants of barley. Anales Aula Dei. 2:149-167.

Tsuchiya, T. 1971. An improved aceto-carmine squash method, with special reference to the modified Rattenbury's method of making a preparation permanent. Barley Genet. Nwsl. 1:71-72.

Tsuchiya, T. and A. Hang. 1987. Chromosome studies in genus Alstroemeria. Acta Hort. 205:281-287.

Tsuchiya, T., A. Hang, W.E. Healy, and H. Hughes. 1987. Chromosome studies in the genus Alstroemeria. I. Chromosome numbers in 10 cultivars. Bot. Gaz. 148:519-524.

Uphof, J.C.Th. 1952. A review of the genus $A l$ stroemeria. Plant Life: Herbertia Ed. 8:36-53.

Whyte, R.O. 1929. Chromosome studies. Relationship of the genera Alstroemeria and Bomarea. New Phytol. 28:319-343.

Zohary, D. 1970. Centers of diversity and centers of origin, p. 33-42. In: O.H. Frankel and E. Bennett (eds.). Genetic resources in plantsTheir exploration and conservation. F.A. Davis Co., Philadelphia. 